\title{
Patrimonialização de Narrativas Orais e o Debate sobre os Direitos Individuais e Coletivos
}

\author{
Herom VARGAS \\ Monica IAFRATE \\ Priscila Ferreira PERAZZO
}

Vilma LEMOS

(IMES)

Resumo: Propondo o registro da memória e do patrimônio cultural do $\mathrm{ABC}$ a partir de gravações de histórias de vida narradas pelos moradores da região, orientadas pelas técnicas de história oral, o Núcleo de Pesquisas de Memórias do $A B C$, da Universidade Municipal de São Caetano do Sul - IMES, depara-se com uma gama de direitos do cidadão. Por isso, este texto tem como objetivo refletir sobre patrimonialização de narrativas orais e direitos individuais e coletivos que envolvem o processo de constituição do patrimônio cultural.

Palavras-chave: Narrativas orais; Patrimônio cultural; Direitos; Memória

Abstract: This study deals with the documentation of ABC cultural memory and heritage, as a result of fieldwork where the recording of life story narratives have been collected. The Memory of ABC, University Municipal of São Bento Caetano Sul (IMES) faces some civil rights allegations, therefore the objective of this essay is to reflect on the heritage of oral narratives, individual and collective rights which make up the cultural heritage.

Keywords: Oral Narratives; Cultural Patrimony; Private rights; Memory

\section{Introdução}

Atualmente, as ciências têm caminhado, cada vez mais, na direção de propostas multidisciplinares, envolvendo o estudo de vários aspectos de determinado objeto para sua melhor compreensão. Ao tomar tal idéia como base, este texto tem a intenção de apresentar a 
discussão da patrimonialização ${ }^{1}$ de informações e bens privados por parte dos pesquisadores das humanidades, da linguagem e da comunicação, que não podem se furtar de adentrar pelas perspectivas jurídico-legais e éticas, uma vez que, hoje em dia, tais questões envolvem, fomentam e transformam o processo assinalado de forma ampla e inovadora dentre as demandas de direitos exigidos pela sociedade atual.

Questões como essas fazem parte das discussões e debates internos no Núcleo de Pesquisadores Memórias do $A B C$, que se desenvolve na Universidade Municipal de São Caetano do Sul - IMES, sob as temáticas da memória, narrativa oral e patrimônio cultural regional. $\mathrm{O}$ Memórias do $A B C$ propõe o registro da memória e do patrimônio cultural das cidades de Santo André, São Bernardo do Campo e São Caetano do Sul, na região metropolitana de São Paulo, a partir de gravações de histórias de vida narradas pelos seus moradores, orientadas pelas técnicas de história oral. Na produção dessa documentação, que se pretende liberar não só à comunidade acadêmica, mas também ao público em geral, depara-se com uma gama de direitos do cidadão. $\mathrm{O}$ que se pretende aqui é fazer uma reflexão sobre essa relação entre patrimonialização de informações e bens pessoais privados e a gama de direitos envolvidos. ${ }^{2}$

A Universidade IMES produz, com suas pesquisas, um acervo de memória e história oral. A partir da gravação de depoimentos de moradores do $\mathrm{ABC}$, que cedem as informações de suas histórias de vida e seus objetos pessoais, guardados como relíquias, constitui-se o HiperMemo - Acervo Hipermídia de Memórias do ABC, considerado patrimônio cultural dessa comunidade.

${ }^{1}$ Quando um documento, seja ele uma fonte oral, um documento escrito, fotografia ou objeto, entra em uma instituição como uma universidade, museu, centro de documentação ou arquivo público, ele se transforma: perde sua função e seu valor original de um bem individual e ganha nova significação e valor como um bem coletivo e passa a integrar a categoria de patrimônio cultural.

${ }^{2}$ No intuito de propor um debate multi e interdisciplinar que orientasse e promovesse diversas discussões, realizou-se, no Núcleo de Pesquisadores de Memórias do ABC/Universidade IMES, em 18 de setembro de 2004, o Seminário "Aspectos Legais do Registro e Divulgação de Informações Pessoais", com as comunicações de Monica Iafrate e Otacílio Pedro de Macedo. O seminário tinha como finalidade discutir a dupla característica dos direitos individuais e coletivos, no que diz respeito à constituição do patrimônio cultural. 
Os depoentes, muitas vezes, relatam situações não registradas em nenhum outro lugar, por nenhuma outra fonte histórica, muito menos pelos documentos públicos e oficiais. Seus objetos (como fotografias, certificados, cartas, roupas, discos etc.) estão sendo recuperados, pois se configuram como fontes documentais que, normalmente, não encontram réplica nos arquivos municipais ou estaduais ou mesmo nos museus. Muitas histórias são retiradas do esquecimento e, ao serem contadas, apresentam-se como versões que não tiveram vez nos registros acadêmicos e retratam formas de vida, de pensamento e de visão de mundo distintas das versões da história oficial.

\section{A História Oral como método para o registro de narrativas e histórias de vida}

Os registros das narrativas orais e das histórias de vida dos moradores do ABC pautam-se em Aspásia Camargo e Verena Alberti (1990), que desenvolveram, a partir de 1975, o acervo de história oral no Centro de Documentação Contemporânea da Fundação Getúlio Vargas do Rio de Janeiro (CPDOC-FGV-RJ). Os depoentes contam sua história de vida desde sua infância até o momento atual. Seus relatos são gravados no estúdio da Universidade, durante uma hora, em fitas de vídeo mini-dv e em fita cassete de áudio. Em algumas situações, dada a riqueza de informações, esse tempo é ampliado.

No Memórias do $A B C$, os depoentes são selecionados a partir dos objetivos temáticos das pesquisas realizadas. Desde 2003, já foram desenvolvidos temas nas áreas de: cinema, teatro, trabalho, gênero, desenvolvimento de cidades, movimentos culturais, imprensa alternativa, música popular e meios de comunicação, imigração, II Guerra Mundial e a própria Universidade IMES. As entrevistas são acompanhadas por entrevistadores, que seguem um roteiro estabelecido a partir da própria cronologia da história do entrevistado, ressaltando suas experiências acerca do tema da pesquisa em desenvolvimento. Dadas as temáticas estudadas até o presente, o acervo do Memórias do $A B C$ compõe-se de cerca de 145 histórias de vida e cerca de 2000 objetos digitalizados e armazenados sob forma de imagem.

Ainda que o roteiro das entrevistas seja conduzido por perguntas, o depoente fica à vontade para assumir seu papel de 
"contador" e a narrativa ocorre sem muitas intervenções dos entrevistadores. A partir de uma relação de confiança e certa intimidade entre entrevistador e entrevistado (ou pesquisador e depoente), as entrevistas cumprem sua função: dar voz aos anônimos cujas vidas também contam histórias não menos importantes do que as histórias oficiais ou conhecidas.

Destaque-se que, mesmo relatando suas lembranças do passado a partir das referências impostas pelo presente, fator de subjetividade, a soma das histórias de outros depoentes de mesma temática, ou do mesmo período, pode auxiliar na compreensão de determinados fatos.

\section{Patrimonialização de informações e bens pessoais}

À medida que os depoimentos de história de vida das pessoas e seus objetos pessoais transformam-se em fontes históricas acessíveis, tem-se a produção de documentos históricos, ou seja, objetos carregados de sentido e colocados à disposição do público interessado em decodificá-los para o entendimento da sua história. Conseqüentemente, devem ser vistos sob a perspectiva de um conjunto de bens de valor histórico, definidores das identidades culturais de uma sociedade, colocados novamente à disposição dessa coletividade para seu uso simbólico. Em outras palavras, sob a perspectiva do patrimônio cultural. Segundo Marly Rodrigues,

A noção de patrimônio tem se ampliado e hoje o entendemos como parte da memória da sociedade, um amplo e diversificado conjunto de bens [...]. Por meio do patrimônio as sociedades criam formas de representação do passado nas quais se justificam valores que fundamentam as relações sociais no presente; ele é um lugar de memória que permite compor imagens que sustentam identidades individuais e coletivas. (RODRIGUES, 2000, p. 145)

No entanto, a origem desses depoimentos de vida e dos objetos pessoais cedidos às instituições universitárias e de documentação e pesquisa histórica é, eminentemente, individual. Eis, no sentido coletivo da patrimonialização de documentos, que surge a questão dos direitos privado, moral e patrimonial. 
Por acreditar na importância da recuperação de informações e bens das pessoas comuns, o Memórias do $A B C$ e a Universidade IMES assumiram o dever de enfrentar a discussão da cessão de direitos que rege a questão do patrimônio privado. Nesse sentido, de forma ética e comprometida, é preciso refletir sobre a transformação de um acervo pessoal privado em patrimônio cultural. Visando conceder ao público e à comunidade seu patrimônio de forma ampla e irrestrita, sem ferir as premissas legais que garantem os direitos dos autores e proprietários de bens, torna-se papel político e ético do pesquisador, do guardião e do gestor da memória coletiva abrir o debate interdisciplinar para, de forma democrática, atuar em favor das liberdades, conquistas e direitos alcançados hoje em dia.

Um procedimento ético na gestão documental está em cumprir todas as disposições legais estabelecidas para esse campo de ação. A ética também está vinculada a uma visão contemporânea do que é patrimônio e de como ele deve ser preservado. O gestor não pode tomar partido em questões conflitantes. Ele deve zelar pela preservação do patrimônio, garantindo a sua fidedignidade. Nos dias atuais, essa questão da manipulação de informações contidas em documentos fica ainda mais complexa quando se trata da documentação eletrônica, cuja problemática, específica demais, não será abordada neste espaço.

No caso da restauração de bens culturais, por exemplo, os procedimentos devem ser adotados a fim de garantir a sua "documentalidade" e fidedignidade e não fazê-los parecer "novos" à custa de alterações e descaracterizações. Esses princípios têm sido estabelecidos por convenções internacionais - as Cartas Patrimoniais recomendadas pela Organização das Nações Unidas para a Educação, a Ciência e a Cultura (UNESCO). Essas questões, embora não estabelecidas por poderes públicos, ainda que reconhecidas por eles, resultam da reflexão e do trabalho de profissionais que se organizam para a criação de códigos de ética. ${ }^{3}$

\footnotetext{
${ }^{3}$ Exemplos de organizações que elaboraram recomendações a serem seguidos por profissionais de suas áreas são: Código de Ética do ICOM (Conselho Internacional de Museus) e Código de Ética do ICA (Conselho Internacional de Arquivos).
} 
Ainda há o debate em torno do dever público e coletivo do patrimônio histórico-cultural e dos direitos individuais dos que cedem seus objetos às instituições. Um cidadão, uma instituição ou uma empresa pode se dedicar ao registro de sua própria história e à organização de seu acervo documental para uso próprio, sem disponibilizá-lo ao público, pois trata-se de seu patrimônio, inserido nas dimensões do Direito Privado.

No entanto, no caso da produção documental que vem sendo constituída pelo Memórias do $A B C$, na Universidade IMES, as pesquisas pretendem compor uma coleção que nada mais é do que um patrimônio cultural. Essa característica impõe outra conduta diante do uso e dos direitos de acesso à documentação, pois um depoimento de história de vida deverá compor uma base de dados sobre a memória coletiva. Esse processo de ressignificação do depoimento pessoal, que gerou um patrimônio cultural, é denominado, aqui, de patrimonialização de narrativas orais.

Assim, quando um documento se configura como patrimônio, automaticamente, ele passa para a esfera pública. Sobre essa posição, incidem outras implicações, porque, como bens culturais, testemunhos de uma época passada e guardiões de uma memória, ao mesmo tempo individual e coletiva, formam a herança cultural de uma coletividade.

Segundo Eunice Durham, a formação de um sentimento de Nação está intimamente ligada à identificação de um patrimônio comum.

A verdade é que um Estado Nacional não se organiza a não ser através da criação cultural de um patrimônio comum e de uma identidade própria. Não tem outro modo de criar uma sociedade a não ser através disto. [...] Como as nações são organizadas pelo Estado, e a nação só pode funcionar através de um patrimônio comum (que é o que dá idéia de nação) que legitima o Estado, é necessário esse processo. O Estado faz isso mesmo que não queira, e não vejo outro modo de ter um Estado Nacional sem isso. Nós podemos dizer que devemos lutar politicamente para que isso seja menos espoliativo, menos violento e que não implique a destruição de diversidades culturais existentes. (DURHAM, 1994, p. 44) 
Essa noção de patrimônio é muito importante para entender o valor do acervo que está sendo organizado. Ele deixa de ter valor de uma memória individual e passa a ser herança cultural dessa cidade, dessa região, desse Estado, que, em última instância, é uma herança nacional. Configura-se, assim, a passagem de coleção privada, do uso do direito privado, para o direito de uma memória coletiva.

Vários pesquisadores na região do $\mathrm{ABC}$ vêm se dedicando, nos últimos anos, a refletir acerca de possíveis identidades regionais. Inicialmente, parte-se da história de um "subúrbio industrial", da concepção do lugar da produção, do trabalho e da vida operária. No entanto, discutem-se processos de identificação regional, questões de trabalho e industrialização, mas também aspectos de produção artísticocultural e cotidiano das cidades e das pessoas. Diante de um "verdadeiro movimento em favor da história regional" (MARTINS, 2002, p. 17) do $A B C$, esse núcleo de pesquisas volta-se para a constituição de um acervo de histórias de vida, na perspectiva da patrimonialização de narrativas orais.

No entanto, há um aspecto importante a ser observado nesse processo de patrimonialização. Apesar de o documento se tornar um bem público, alguns direitos privados (os autorais, de uso da imagem etc.) vinculados aos seus antigos proprietários ainda são mantidos. $\mathrm{O}$ fato de eles se transformarem em bem público não interferirá nesses direitos. O mesmo acontece num processo de tombamento. Ao tombar um bem, a legislação não impede o direito de propriedade, mas cria restrições a esse direito, no intuito de preservá-lo na sua integridade e fidedignidade. Existe também, nesse processo, um compartilhamento de responsabilidades por essa memória, por esse documento: ele deixa de ser apenas da pessoa que o detinha para ser também da instituição que se torna sua guardiã.

\section{Direitos privado, moral e patrimonial}

No âmbito da patrimonialização de um bem privado, são duas as questões: uma de natureza pública e outra de natureza privada. Para discuti-las, é preciso abordar o direito autoral, cujos direitos morais decorrem do direito autoral, que reconhece ao autor a patrimonialidade da obra como atributo da sua personalidade. Significa, assim, afirmar que o direito autoral é uma emanação de valores que nasce da pessoa, 
daquela que constrói um bem de acordo com suas capacidades, portanto, de caráter subjetivo. $\mathrm{O}$ direito autoral como um direito patrimonial, incorpóreo ou imaterial reconhece ao seu dono a prerrogativa de dispor dele ou de fazer uso econômico dele, o que nada mais é do que poder alienar essas emanações, esses valores que foram construídos e elaborados pelo autor. ${ }^{4}$

Levar em conta as premissas de duplo conteúdo do direito autoral (um de ordem moral e outro de ordem patrimonial) implica saber a natureza jurídica desse direito autoral com vistas a outro aspecto: o domínio da propriedade ou do patrimônio. Alguém detém essa propriedade, conseqüentemente, alguém detém esse domínio. Nessa perspectiva, é importante saber quem vai se utilizar dessa propriedade e a que título o fará, pois, tratando-se de uma propriedade a ser utilizada por outra pessoa, é necessário que seu dono a disponibilize, ou então disponha dessa propriedade.

Não se tem a pretensão, nesse momento, de tentar distinguir disponibilização de disposição, mas arrisca-se a discutir que não é só disponibilizar para alguém utilizar. A questão inclui também dispor, ou seja, vender sob determinados interesses, sob doação ou alienação. Se é alienação, pode ser doação temporária, perpétua, uma doação com restrição, ou então é uma doação sob condição. De uma forma ou de outra, mesmo entendendo os valores ou as extensões dos direitos autorais, o enfoque vai sempre envolver um aspecto: é uma propriedade de alguém, um bem jurídico. Apesar de sua destinação voltar-se para a promoção do bem cultural, não deixa de ser um bem com certo valor econômico. Nesse ponto reside uma problemática. ${ }^{6}$

Por oportuno, a lei hoje em vigor que trata do direito autoral (Lei $\mathrm{n}^{\circ}$ 9610/1998) prescreve além do tempo de vida do autor, permitindo-lhe dispor dessa propriedade da maneira como quiser. Durante sua vida, o autor pode explorar seu bem. Após sua morte,

\footnotetext{
${ }^{4}$ Comunicação de Otacílio Pedro de Macedo no Seminário "Aspectos legais do registro e divulgação de informações pessoais", realizado na Universidade IMES em 18 de setembro de 2004. Explica-se que as exposições desse seminário não chegaram a ser publicadas, o que nos obriga a remeter as referências desses dados para as palestras.

${ }^{5}$ Comunicação de Otacílio Pedro de Macedo, 2004 (cf. nota 4).

${ }^{6}$ Comunicação de Otacílio Pedro de Macedo, 2004 (cf. nota 4).
} 
seus sucessores têm o mesmo direito por mais 70 anos, para então essa propriedade cair no domínio público. Mas a questão ainda é mais complexa, porque, no direito privado e, mais precisamente, no direito das sucessões, ocorre que o dono da propriedade, na hipótese de ele ter sucessores, só poderá dispor do que a lei lhe permite. No direito autoral, a pessoa não pode dispor sozinha da totalidade dessa propriedade.

Quais são as implicações dessa legislação no caso da patrimonialização de informações e bens privados? Isso implica estabelecer a forma como seu proprietário irá dispor desse bem. Pode ser a título oneroso ou a título gratuito. Pode ser uma doação pura e simples, sem condições, ou uma doação sob condição e, neste caso, pode assumir a forma de doação com encargos ou testamentária, por exemplo. Saber se os bens doados terão uso comercial ou terão apenas finalidade cultural, histórica ou acadêmica determinará, certamente, a forma de dispor dos bens, abrindo mão de seus direitos autorais. ${ }^{8}$

As pessoas que prestam depoimentos ou que doam seus acervos particulares para instituições de caráter público têm o direito de estabelecer condições para a sua disponibilização. Elas podem estabelecer, por exemplo, prazos para que se tenha acesso, como foi o caso da documentação e das coleções de objetos e obras de arte do escritor Mário de Andrade. Em seu testamento, ele estabeleceu, para um lote de documentos, um prazo específico a ser observado antes de sua abertura ao público. Coube ao Instituto de Estudos Brasileiros da Universidade de São Paulo (IEB-USP), que tem a guarda dessa documentação, fazer valer essas disposições testamentárias. Os doadores podem criar limites ou determinar que trechos não sejam disponibilizados. Podem também determinar quem pode ou não ter acesso à documentação. Caberá à instituição que recebe a guarda da coleção, tornar essa documentação o mais acessível possível, em nome do seu valor de memória coletiva. É uma negociação que deve ser feita entre as duas partes. O objetivo dos documentalistas, como profissionais que cuidam e disponibilizam um acervo de memória coletiva é lutar para que ela seja o mais aberta e acessível possível. Mas também é sua função zelar para que as eventuais restrições sejam respeitadas.

\footnotetext{
${ }^{7}$ Comunicação de Otacílio Pedro de Macedo, 2004 (cf. nota 4).

${ }^{8}$ Comunicação de Otacílio Pedro de Macedo, 2004 (cf. nota 4).
} 
No caso de produção documental a partir do relato das pessoas, mantém-se o direito autoral de quem produziu o documento e o direito de uso da imagem. Ao mesmo tempo, há uma responsabilidade na disponibilização dos seus conteúdos. A responsabilidade pela preservação dos direitos individuais embutidos nesse patrimônio público ficará a cargo das instituições que o tiverem sob sua tutela. Caberá aos documentalistas responsáveis pela gestão desse patrimônio ter o conhecimento da legislação e das questões vinculadas a elas, a fim de garantir o respeito aos entrevistados.

Os doadores podem também solicitar a confidencialidade de algumas informações a seu respeito. Por exemplo, nos museus de arte, muitos deles não permitem a divulgação de seus nomes. Quando essas informações contribuem para o saber, deve-se advertir o proprietário do interesse que representa a sua difusão. No entanto, essas informações não devem ser publicadas e nem comunicadas a nenhuma instituição ou pessoa sem autorização específica do proprietário. A confidencialidade está subordinada à obrigação legal de informar à polícia ou a outros órgãos competentes, no caso de investigação de bens que podem ter sido roubados, adquiridos ou transferidos de maneira ilícita. Existem questões de segurança e de garantia de direitos. A divulgação de qualquer informação não autorizada irá onerar a instituição responsável pelo patrimônio doado.

Outra dimensão dos direitos do cidadão refere-se ao direito à informação, ou seja, como o poder público ou a instituição vai disponibilizar uma informação e se esta é de propriedade de alguém. Nesse sentido, deverá ocorrer a mediação do poder público entre aquele que dispõe de suas informações patrimonializadas e o guardião do patrimônio cultural. De uma forma ou de outra, tal questão incide sobre um direito privado que, por sua vez, também incide sobre um interesse coletivo. Eis outra polêmica e, muitas vezes, fonte do conflito. ${ }^{9}$

Caberá aos arquivistas, documentalistas e demais profissionais responsáveis pelos acervos em instituições de preservação e difusão patrimonial encontrar o justo equilíbrio, no quadro da legislação em vigor, entre o direito ao conhecimento e o respeito à vida privada. A busca desse equilíbrio tem de ser um objetivo ético-profissional. Há um direito privado a ser respeitado, da mesma forma que se deve

${ }^{9}$ Comunicação de Otacílio Pedro de Macedo, 2004 (cf. nota 4). 
garantir o direito ao conhecimento. Contudo, tais questões são muito complexas. Os arquivistas preocupam-se para que as vidas das pessoas jurídicas e físicas, assim como a segurança nacional, sejam protegidas sem que haja necessidade de destruir as informações, sobretudo no caso dos arquivos informatizados, em que os dados podem ser apagados ou substituídos por outros.

A discussão não permanece apenas em torno do direito à propriedade. Ainda é necessário ressaltar que, mesmo ao renunciar a esse direito, o autor ainda se reserva o direito moral, subjetivo, traduzido por um sentimento. Mesmo que não utilize esse patrimônio para uma finalidade comercial, o autor, por razões de valores morais, poderá reclamar não a indenização, mas a forma de disponibilização, ou mesmo a proibição de suas informações doadas, se considerar que provocam danos morais à sua pessoa. ${ }^{10}$

Os arquivistas defendem o respeito à vida privada das pessoas que estão ligadas à origem ou que são a própria matéria dos documentos, sobretudo daquelas que não foram consultadas quanto à sua utilização ou ao seu destino. Por exemplo, pessoas citadas por outros podem vir a se sentir ofendidas e pretenderem alguma restrição, considerando algum dano moral ou material. Por isso, a ética deve constituir-se no respeito ao que a legislação prevê para aquela documentação. ${ }^{11}$

A instituição que é tutora legal desses documentos também tem o dever de fazer algumas restrições. Existem prazos legais, no direito constitucional de autoria, que devem ser zelados e divulgados pela instituição guardiã dos acervos patrimonializados. É seu dever abrir essa documentação para consulta pública, cercando-se, contudo, de todos os mecanismos legais.

Há outra situação em que podem ser criadas restrições: tratase de quando a preservação desse patrimônio é ameaçada, dentre outras razões, por um estado precário de conservação, criando a necessidade de outra forma de disponibilizar a informação, não só para a geração presente, mas para as gerações futuras.

\footnotetext{
${ }^{10}$ Comunicação de Otacílio Pedro de Macedo, 2004 (cf. nota 4).

${ }^{11}$ Mais informações sobre esta questão podem ser obtidas em artigo de Lúcio Henrique Xavier Lopes e João Ricardo Carvalho de Souza (2003).
} 
Neste embate de divulgação e preservação dos direitos privados, as instituições têm a seu dispor instrumentos legais que, muito embora sejam extrajudiciais, podem dar um respaldo para o cumprimento de suas missões (divulgação e preservação do patrimônio cultural). Trata-se de termos e contratos a serem celebrados entre os doadores ou depoentes e as instituições guardiãs, definindo as questões de disponibilização (quando, para quem e o que pode ser disponibilizado). Com relação aos consulentes, os guardiões podem requerer deles termos de responsabilidade sobre a divulgação das informações (ODAIR, 2003, p. 52).

\section{Considerações finais}

Como é possível atentar nesta discussão, a patrimonialização está longe de ser resolvida facilmente. De um lado, existe a premência coletiva pelo uso de um bem considerado patrimônio, dado caracterizador das identidades culturais da comunidade, sobretudo pela importância que a pesquisa histórica vem ganhando em nosso país com a consolidação do processo democrático. Circunscreve-se, nesse processo, o dever de informar a sociedade, da melhor forma possível, sobre seu passado e sobre o entendimento mais coerente do presente com vistas à tomada de ações futuras conscientes e conseqüentes.

Aqui reside uma importância vital dos acervos de história oral. Os depoimentos gravados e patrimonializados nessas instituições carregam uma versão diferente da história oficial. Enquanto esta carrega em si o entendimento da história de um povo a partir dos documentos oficiais escritos, das vozes dos governantes e das elites dirigentes, os depoimentos produzidos pela história oral, por privilegiar aqueles que foram alijados das decisões, retratam outra história: cotidiana, dos processos do trabalho diário, da construção de outras maneiras de viver, da organização familiar, de alternativas de fazer política, de distintas formas de produção artístico-cultural. São discursos refletidos, de alguma forma, na dinâmica da história, porém, avessos às grandes interpretações oficiais e às ordenações burocráticas da sociedade. Mesmo tratando de assuntos por vezes banais e cotidianos, proporcionam um entendimento mais amplo da vida social. Como afirma Paul Thompson: "A evidência oral, transformando os 'objetos' de estudo em 'sujeitos', contribui para uma história que não só é mais 
rica, mais viva e mais comovente, mas também mais verdadeira" (THOMPSON, 1998, p. 137). E essa importância não é menor no caso da região do $A B C$ paulista, onde se estabelece o campo de ação do Memórias do $A B C$.

A constituição do acervo documental regional não se restringe a essas importantes demandas sociais e políticas a que a pesquisa histórica também se atém. O respeito aos direitos individuais circunscritos aos cidadãos que prestam esses depoimentos e cedem objetos pessoais para o acervo das instituições de memória deve ser mantido. Isso deve ser feito da melhor forma possível para resguardar a moral e a imagem dos depoentes, para dignificar o trabalho e a imagem da instituição tutora, para preservar a integridade dos documentos a serem utilizados pela sociedade e, por fim, para regular o usufruto dessas informações, visando ao respeito pelos direitos individuais e pelas demandas coletivas do patrimônio cultural.

Isso não significa que não possa haver algum tipo de pendência ou dúvida de quaisquer das partes envolvidas nesse processo, seja o cedente, seja a instituição, ou mesmo aqueles que farão uso das informações cedidas. Para minimizar possíveis diferenças, é fundamental uma postura ética do profissional que constrói o acervo e zela por ele. Esses cuidados vêm desde a coleta e gravação dos depoimentos, a guarda dos objetos a serem doados por esses depoentes, sua ordenação e classificação, até as formas legais de utilização dessas informações, imagens ou sons por terceiros. Para a guarda, são necessários locais adequados, metodologias de arquivamento e classificação compatíveis com os materiais a serem mantidos, formas claras de acesso disciplinado às informações desses objetos patrimonializados e divulgação ampla do acervo.

De outro lado, no intuito de resguardar os direitos individuais, é importante o uso de instrumentos legais que garantam, jurídica e legalmente, o acesso disciplinado e o uso correto das informações tanto aos depoentes/doadores, como às instituições tutoras e aos terceiros que utilizam os objetos do acervo. Os contratos estabelecidos entre doadores e instituição e entre esta e seus usuários servirão para garantir, sob a égide das leis em vigor, a utilização conseqüente dos dados guardados.

Só assim, mantidos o respeito ao patrimônio cultural e aos direitos individuais dos cidadãos que fazem parte dessa mesma 
sociedade, a história social será guardada. Porém, não apenas preservada, como se entendia antigamente a função dos museus, por exemplo. Trata-se, ao contrário, de uma história que precisa ser diariamente revista e reconstruída a partir das sempre novas demandas dessa sociedade em constante transformação.

\section{Referências}

ALBERTI, Verena. História Oral. A experiência do CPDOC. Rio de Janeiro: FGV, 1990.

DURHAM, Eunice Ribeiro. Cultura, patrimônio e preservação - Texto 2. In: ARANTES, Antônio Augusto (Org.). Produzindo o passado: estratégias de construção do patrimônio cultural. São Paulo: Brasiliense, 1994. p. 23-58.

MARTINS, José de Souza. Subúrbio. Vida cotidiana e história no subúrbio da cidade de São Paulo: São Caetano do fim do império ao fim da República Velha. 2. ed. São Paulo: Hucitec/Ed. Unesp, 2002.

ODAIR, José. Mito, memória e história oral. São Bernardo do Campo: Chamas, 2003.

RODRIGUES, Marly. Imagens do passado. São Paulo: Unesp/Imprensa Oficial/Fapesp, 2000.

THOMPSON, Paul. A voz do passado: história oral. 2. ed. Rio de Janeiro: Paz e Terra, 1998. 